\title{
Scenarios for the South African Water Sector in 2025
}

\author{
M Claassen*, N Funke and S Nienaber \\ CSIR, PO Box 395, Pretoria 0001, South Africa
}

\begin{abstract}
In 2008 the Water Research Commission initiated a project to develop 'Water Sector Institutional Landscape in 2025 Scenarios'. The aim was to build knowledge about key drivers and uncertainties related to the future of the South African water sector. A diverse group of stakeholders contributed to the development of the drivers, which translated into different scenarios and associated stories that have potential implications for social and economic development, as well as for the management of water resources and water services. The four scenarios were derived from a matrix with two axes that represent the ability of the decision-making paradigm of water institutions to deal with complexity, and the reconciliation of environmental, social and economic demands of present and future generations (sustainability). The Wise Tortoise scenario describes a sector which deals with complexity and is sensitive to sustainability issues, whereas the Ignorant Ostrich scenario describes the opposite conditions. The Greedy Jackal and Busy Bee scenarios describe the other combinations of the key drivers. The scenarios provide stakeholders and policy-makers in South Africa's water sector with insights to strengthen decision-making and to counter undesirable trajectories of change. The knowledge will empower role players in the water sector to engage in participative governance by equipping them with insights into potential futures that the South African water sector may face. This paper reports on the process to develop these scenarios for the South African water sector institutional landscape in 2025, presents the key forces, introduces the stories, and reflects on the use of scenarios in the water sector.
\end{abstract}

Keywords: Scenarios, water sector, South Africa, water institutions, water futures

\section{Introduction}

Social development and economic growth are key national and regional priorities (SADC, 2004; NPC, 2011). Socio-economic development depends on the effective deployment of resources, particularly water, with water resources being required for basic human needs and water security being critical for agricultural and industrial development (United Nations, 2003). Decisions and actions in support of this development are often framed with uncertain future conditions, which make it difficult to predict the efficacy of a particular option in the medium- and long-term. These options relate to the way the water sector is organised and to specific decisions for water resource deployment. The Water Research Commission initiated the project 'The Water Sector Institutional Landscape in 2025 ' to build knowledge about key drivers and uncertainties related to the future of the South African water sector. The institutional landscape refers to the context in which water institutions would operate in the future, rather than different operational models or configurations for water institutions. The knowledge about this context, which diverse stakeholders have contributed to during the course of the project, has been translated into different scenarios (with associated stories) that hold potential implications for social and economic development, as well as for water resources and water services. These scenarios provide stakeholders and policy-makers in South Africa's water sector with valuable insights to strengthen decision-making and to counter undesirable trajectories of change. The knowledge also empowers role players in the water sector to engage in

\footnotetext{
* To whom all correspondence should be addressed.

용 +27 12841 2385; fax: +27 12842 7664;

e-mail: mclaasse@csir.co.za

Received 20 March 2012; accepted in revised form 15 January 2013.
}

participative governance through anticipating potential change and planning for effective action.

The knowledge base for the development of the scenarios was developed through structured research, which included an extensive participative process (Claassen et al., 2011a). The authors identified water-related needs, priorities and uncertainties from diverse perspectives through engagement with different stakeholder groups. They also made use of a broad range of methods, such as interactive workshops, semi-structured interviews, social attitude surveys and a web-based survey, to include stakeholders in rural and urban settings and with different cultural and educational backgrounds. Since the project was built on a process of continuous learning and feedback, participants in the research process also improved their understanding of the development and application of scenarios.

\section{Approach}

\section{Emergence of scenario development}

Scenarios are narrative descriptions of a possible state of affairs or development over time, which can be useful to communicate speculative thoughts about future developments to elicit discussion and feedback, and to stimulate the imagination (Warfield, 1996). The concept of scenario planning has its origin in military applications, with the United States Air Force developing 'scenarios' of what the enemy might do and preparing alternative strategies. It was thus aimed at achieving a desired outcome in an uncertain future (Mietzner and Reger, 2004). At the end of the 1940s, researchers at the RAND Corporation (Santa Monica, California) started to investigate the scientific use of expert opinion in planning for the future (Landeta, 2006). The Delphi method became a popular technique for forecasting and decision-making based on the opinions of experts on issues of the future (Glenn and Gordon, 
2003; Landeta, 2006; Banuls and Salmeron, 2007). The Royal Dutch Shell company employed scenario tools to good effect in the 1970s, when they improved their size and profitability by being prepared to act quickly during the oil price shock of 1973 (Daum, 2001). Royal Dutch Shell is often seen to have led scenario development internationally, but Clem Sunter is credited with popularising the use of scenarios in South Africa, with the publication, The World and South Africa in the 1990s, which describes 'High Road' and 'Low Road' scenarios (Sunter, 1987). This specific application of scenarios hailed the beginning of scenario planning in South Africa. Kahane (1996) facilitated a process that became known as the Mont Fleur Scenario Project, which was launched in 1992. It explores the question 'What will South Africa be like in the year 2002?' The Department of Arts, Culture, Science and Technology (DACST) also deployed scenarios and technology foresighting in the development of South Africa's National Research and Development Strategy, with Kahn initiating and leading the development of the South African National Research and Technology Foresight Project (DACST, 1999). In that case, a Delphi approach was followed to derive macro-scenarios. Some of the recent scenario projects in the water sector include the World Business Council for Sustainable Development report on 'Business in the world of water: WBCSD water scenarios to 2025' (WBCSD, 2006), and the Global Research Alliance (GRA) report on Science and Technology-based Water Scenarios for Sub-Saharan Africa (GRA, 2006). The Dinokeng team (2009) developed 3 Futures for South Africa, which characterise future scenarios based on the effectiveness of the state and the engagement of society, whereas the Development Bank of Southern Africa published Prospects for South Africa's Future, which identifies 16 drivers and describes 2 scenarios for South Africa (DBSA, 2011).

\section{Scenario development process}

Schwartz (1991) suggests a 6-step process for the development of scenarios: identifying focal questions; identifying key forces; deciding on driving forces; ranking of driving forces; selecting the scenario logic; and fleshing out the scenarios. In Phase 1 of the process for developing scenarios for the future, the analysis should be framed around a focal question. The question should reflect an issue that is both important and uncertain, or as Schwartz (1991) puts it, 'What is it that keeps me awake at night?' Another framework for scenario development describes a flow path which includes preparation, pioneering, map-making, navigation and reconnaissance (Shell 2003). In this study, the authors followed a combination of the Schwartz (1991) and Shell (2003) processes. The consolidated process is presented in Fig. 1.

The focal question was informed through a project inception meeting and stakeholder engagement. The next steps were to identify key forces in the local environment that would influence success or failure of decisions in the future (Fig. 1, 1b) and to determine driving forces in the macro-environment that influence the key forces (Fig. 1, 1c). These key forces and driving forces were identified through a literature review, personal interviews, social attitude surveys, questionnaires, role play sessions, a web-based survey and expert workshops. The semi-structured interviews included representatives from government, non-governmental organisations (NGOs), water boards, irrigation boards, water research institutions, mining groups, communities, municipalities, conservation agencies, agriculture and environmental activists. A key input to the project was the data derived from the South African Social Attitudes Survey that has been conducted annually by the Human Sciences Research Council (HSRC) since 2003. Questions related to key forces for the development of scenario axes were included in the surveys during 2008 and 2009 and reached 3292 and 3304 people, respectively. The survey included 34 water-related questions that provided useful inputs to the scenario development process. Two of these were openended questions that contributed directly to the identification of key forces. The responses to the open-ended questions were analysed through 'word clouds', to distil the key forces. Word clouds provide a visual impression of reoccurring themes or issues (Halvey and Keane, 2007), with the sizes of representative words in the cloud being proportional to the number of incidences of a particular issue in the responses. These key forces were grouped and ranked in a workshop by determining their degree of uncertainty as well as their impact on the focal question (Fig. 1, 1d).

In the water sector institutional landscape process, the consolidation and ranking were supported by a web-based questionnaire, with each driving force (resulting from consolidating key forces) being accompanied by a brief description and an assessment of its uncertainty and importance on a scale of 1 to 5 . The driving forces were further refined through interaction at schools, which provided inputs from groups of younger South Africans from various parts of the country, who spoke a variety of languages, had a variety of cultural backgrounds, and had diverse educational settings. The interaction included some primary school learners, but mainly high school learners, ranging in age from 12 to 20 years. The questions being asked of the learners required them to reflect on their present context in relation to water as well as to imagine a future picture in relation to the provision of their water needs. The construction of the scenario logic is the first step in Phase 2 of the scenario development process (Fig. 1, 2a). Strategic conversations were held with thought leaders in the sector to refine the context, players, certainties, key uncertainties and the scenario outline. This resulted in the agreement on the scenario logic and provided key elements for fleshing out the scenario stories (Fig. 1, 2b). In the third phase of map-making, these inputs

\begin{tabular}{|l|l|l|}
\hline 1. Preparation & 2. Pioneering \\
a. Focal question & & \multicolumn{1}{|l|}{ 3. Map-making } \\
b. Key forces & a. The scenario logic \\
c. Driving forces & b. Fleshing out scenarios \\
d. Ranking & & 4. Navigation \\
\hline
\end{tabular}

Figure 1

The process followed for the development of the South African Water Sector Institutional Landscape in 2025 Scenarios (Adapted from Schwartz, 1991 and Shell, 2003). 
Figure 2

Word clouds derived from responses to the questions: a) 'If water is poorly managed by the municipalities and misused by the people, what do you think will happen?' and b) 'How can the government make sure there is safe drinking water for all in the future?'

\begin{tabular}{|cc|}
\hline a & \\
Chaos & Suffer Chirst Bad \\
Death & Cholera \\
Scarce & Shortage Crisis \\
Expensive Disease/Sick \\
Drought
\end{tabular}

\begin{tabular}{|c|cc|}
\hline b & \multicolumn{2}{c|}{ Manage(ment) Purify(ing) } \\
Build Check(ing) \\
Chemicals Clean(ing) Save \\
Teach $\quad$ Dam(s) \\
Educate $\quad$ Conserve(ation) \\
\hline
\end{tabular}

were combined with the driving forces and used to populate the stories around the scenario logic. The navigation and reconnaissance phases are related to the 'Picture of Now' (Society for International Development, 2005), with accounts of the current context and desired trajectories of change being provided by A CSIR Perspective on Water in South Africa (CSIR, 2010), the National Development Plan: Vision for 2030 (NPC, 2011) and the 2011 Annual Report of the Department of Water Affairs (DWA, 2011).

\section{Results}

Following the process in Fig. 1, the focal question (Step 1a) was identified as: 'What are the most important and uncertain driving forces that will impact on the South African water sector institutional landscape by 2025 and what could the future look like under different configurations of these key forces?' The key forces that are likely to affect the water sector institutional landscape by 2025 were identified through individual interviews, social attitude surveys and a web-based survey (Step $1 b$ in Fig. 1). The results from the closed questions in the South African Social Attitudes Survey (Roberts et al., 2010) provided useful contextual information, whereas the open-ended questions provided useful inputs to key forces. The word clouds presented in Fig. 2 summarise the issues and concepts that were derived from the open-ended questions in the South African Social Attitudes Survey.

Key forces identified through the various engagement methods were consolidated to inform the formulation of driving forces. The use of different methods to gather information for the development of scenarios highlighted certain strengths and weaknesses in these approaches. While the web-based survey allowed easy access for many potential respondents, the number of responses was relatively low. This response rate was in line with other similar surveys (Kaplowitz et al., 2004). The respondents rated the suggested driving forces in terms of importance and uncertainty, but there were no suggestions for additional driving forces. The forces and associated descriptions were communicated and further inputs invited through summary documents, conference presentations and workshop discussions. Discussions and role-play sessions at various schools provided additional inputs to the forces. The 27 driving forces that were consequently identified as important influences on the water sector towards 2025 are listed in Table 1.

The driving forces described in Table 1 were used to construct the scenario logic, which provided the outline for learners at several schools to provide further inputs and contribute stories of the future. The conversation resulting from these interactions produced a wide range of thoughts and ideas. Learners were particularly concerned about the impact of mining on water quality and how this reduced water quality would impact on farmers, farmland and poorer communities. They also felt that greater monitoring of mines and enforcement of legislation was important. Learners also felt that better technology will be needed in future to farm with less water, and alternative industries would need to be promoted. They expressed a concern that water will run out as a result of growing human, power and economic needs. They also felt that technological solutions like desalination may help in future. Learners felt that alternatives to municipally-purified water may be necessary in rural areas that lack basic access to water (e.g. filtration and bleach purification) and worried about the lack of personal responsibility that South Africans take for water. Finally, they felt that household-level conservation and water awareness will be increasingly important in future.

During the strategic conservation workshops, which was the next mode of stakeholder interaction, the scenario logic was established, which featured 2 pivotal issues as axes (Illbury, 2011; Claassen et al., 2011b). These pivotal issues, which represented themes of the above driving forces, were defined as follows:

- Ability of decision-making paradigm to deal with complexity

- The reconciliation of environmental, social and economic demands of present and future generations, i.e. sustainability

The pivotal issues resulted in the development of 4 scenarios (Fig. 3). Each scenario was assigned a popular title, as is the practice in scenario development (GRA, 2006; Dinokeng Team, 2009; DBSA, 2011). These names aid in the characterisation, communication and application of the scenarios. In the 'Wise Tortoise' scenario, the decision-making paradigm deals with complexity, and is keenly sensitive to sustainability issues. In the 'Busy Bee' scenario there is a keen sensitivity to sustainability issues but the decision-making paradigm fails to deal with complexity. In the 'Ignorant Ostrich' scenario, there is exploitation regardless of sustainability and the decisionmaking paradigm fails to deal with complexity. The 'Greedy Jackal' scenario represents a future where the decision-making paradigm deals with complexity but where exploitation continues regardless of sustainability.

Literature on complexity supports the identification of this issue as a driver for scenarios. Complex systems exhibit the following: a large number of interacting elements; non-linear relationships between elements; system characteristics are emergent; the system integrates the past and present and this evolution is irreversible; the past is not a good predictor of the future; and forecasting is difficult (Snowden and Boone, 2007). Rogers et al. (2000, p. 509) list 'dealing with uncertainty, complexity and change as given factors' as one of the required inputs for securing a nurturing institutional environment, whereas Pollard and Du Toit (2008) argue that management approaches of the past have failed to deal adequately with the challenges posed by complex and rapidly changing systems.

Stories were written for each scenario, which described what the world would look like under each of the four conditions. The purpose of stories is for people to imagine a future 


\begin{tabular}{|c|c|}
\hline \multicolumn{2}{|c|}{$\begin{array}{l}\text { Table } 1 \\
\text { Questions and resultant driving forces for the water sector institutional landscape in } 2025\end{array}$} \\
\hline Questions & Driving force \\
\hline Are long-term plans in place to achieve objectives for the future? & Strategic planning \\
\hline Is the water sector prioritised at the political level? & Prioritisation \\
\hline Are other sectors able to provide reliable supplies of goods and services to the water sector? & Inter-sectoral coordination \\
\hline Are water users and polluters required to cover the real cost of their use, including externalities? & Economics of water \\
\hline Are water resource management and water services privatised? & Privatisation \\
\hline Does regulation ensure a culture of compliance and cooperative management in the water sector? & Regulation \\
\hline $\begin{array}{l}\text { Are responsible agencies able to issue water use licences to support sustainable social and eco- } \\
\text { nomic development? }\end{array}$ & Water use licensing \\
\hline Does a shortage of skills prevent the water sector from being effective? & Skills \\
\hline Does high staff turnover prevent the water sector from being effective? & Staff turnover \\
\hline $\begin{array}{l}\text { Is funding for monitoring, evaluation and maintenance available and deployed to ensure continued } \\
\text { and sustainable delivery of services? }\end{array}$ & Funding for operations \\
\hline Are technology and technology-related services global? & Globalisation \\
\hline $\begin{array}{l}\text { Does the development of new technologies keep pace with the challenges in the sector and are } \\
\text { available technologies deployed in the sector? }\end{array}$ & Technology development \\
\hline Does civil society participate in water governance? & Civil society \\
\hline Do water user groups feel that they have fair and equitable access to water governance processes? & Equitable participation \\
\hline Do communities have a sense of ownership of water resources and associated infrastructure? & Ownership \\
\hline Is the water sector able to respond to global change? & Global change \\
\hline $\begin{array}{l}\text { Do national and regional political contexts create an environment which is conducive to the effec- } \\
\text { tive functioning of water institutions? }\end{array}$ & Political stability \\
\hline Is the public water sector decentralised and are decisions devolved to a local level? & Decentralisation \\
\hline Is local government able to meet the demands of the water sector? & Local government \\
\hline Are rights to water translated into action? & Rights to water \\
\hline Do land restitution and transformation in land ownership lead to more effective water use? & Land restitution \\
\hline $\begin{array}{l}\text { Do implementation of water sector policies and regulation achieve an equitable balance between } \\
\text { providing services, utilising the resource and achieving sustainability? }\end{array}$ & $\begin{array}{l}\text { Balance development and } \\
\text { protection }\end{array}$ \\
\hline $\begin{array}{l}\text { Does water governance take account of the physical, chemical and biological complexity and } \\
\text { constraints of the resource? }\end{array}$ & Biophysical constraints \\
\hline How does poor water quality affect users and impact on real social and economic development? & Water quality \\
\hline Is the water sector recognised as a critical driver for social and economic growth? & Social and economic growth \\
\hline Is a regional approach taken in water-related social and economic development? & Regional development \\
\hline $\begin{array}{l}\text { Does disease, such as HIV/AIDS, diarrhoea, and cholera change demands for water resources and } \\
\text { services? }\end{array}$ & Disease \\
\hline
\end{tabular}

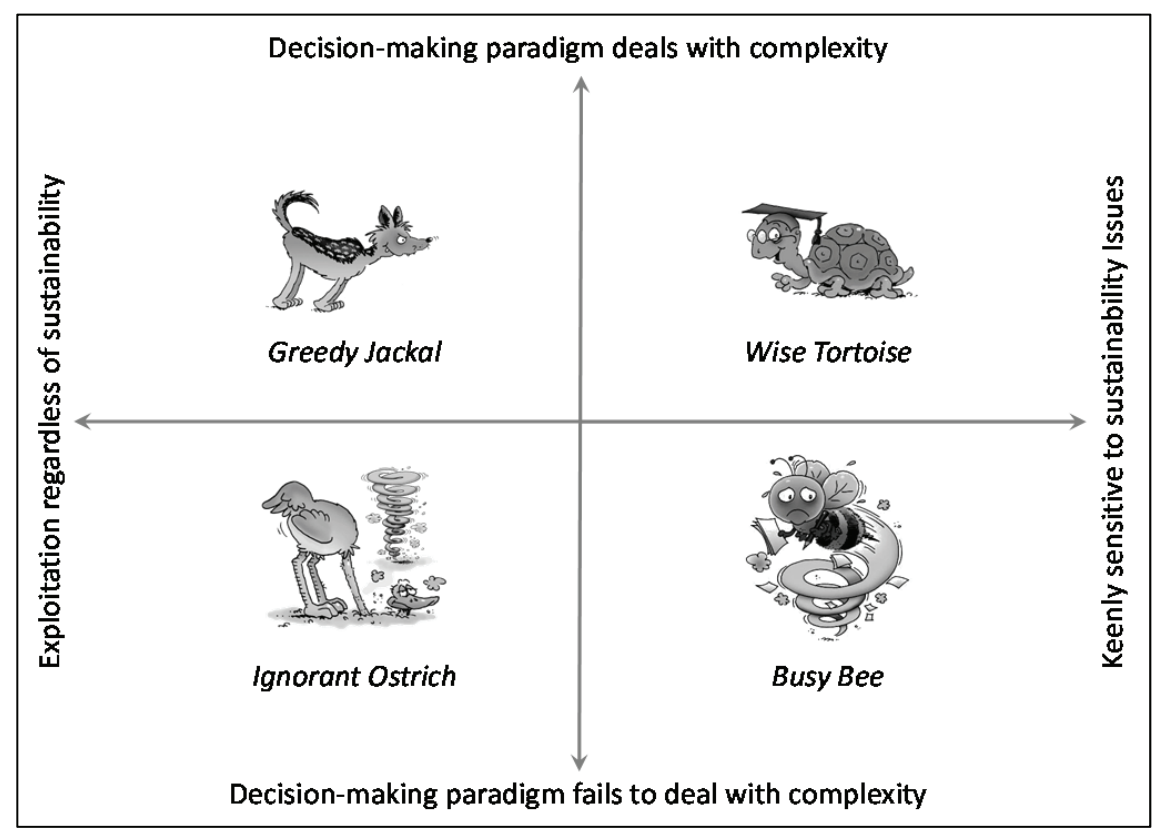

Figure 3

Scenario game board with complexity on the $Y$-axis and sustainability on the $X$-axis 
under certain conditions and to visualise possible consequences of such a future. The stories are therefore not predictions, or the truth, but represent plausible futures. This process helps people to identify preferred future states, recognise trajectories and agents of change and take action to realise a desired future. Likewise, people can also take steps to mitigate risks that certain future conditions could bring about. Characters with traits that could be associated with the scenarios were chosen to aid in communication. The Wise Tortoise comes from the children's story of the race between the tortoise and the hare, which demonstrates the value of a methodical approach. The Busy Bee illuminates the scenario where there is good intent and effort, but ignorance of complexity foils these efforts. The Ignorant Ostrich follows the myth that ostriches stick their heads in the sand when there is danger. The Greedy Jackal is very sly and deals with complexity but exploits resources in an unsustainable way.

In the story of the Wise Tortoise, a paradigm shift has occurred. There is no isolated and singular 'water sector'. Instead, it is a multi-layered and diversified composite of different sectors all actively engaged in water as a resource of strategic importance. This has been achieved through the increased harmonisation of legislation and is guided by a shared, principle-based vision. This means that transaction costs are reduced and the tools used extend beyond command-and-control. There is now a state of institutional maturity and stability, one that recognises legal plurality and alignment with a confidence to embrace flexibility; it is, in essence, an enabling environment that allows governance to work. Moreover, it harnesses indigenous knowledge, values and decision-making processes. Strong decentralised systems allow for local regulation, and for local impacts to be addressed. As people become more empowered to make choices and decisions, a strong citizens' voice starts to emerge. Combined with successful incentives, this has encouraged accountability by all stakeholders, from individuals through corporations and up to government. A tortoise will prosper when it has a complete understanding of its environment, and allocates the correct resources timeously, with great thought, and with conviction. In this scenario, a common understanding and awareness by all stakeholders has led to the appreciation of the true value of water to self and to others. It is recognised as both a social and an economic resource, but more importantly a finite one, which should therefore be protected and carefully managed. The environment flourishes, providing a sustainable resource of clean and re-usable water. The outcome of this scenario is a happy and prosperous people.

The story of the Busy Bee is characterised by noble intentions but a failure to correctly execute requisite actions. Part of the reason for this is a distorted perception of the state of affairs. The country has enough water - or so it seems - and there is a genuine zeal on the part of the government to ensure that it remains so, and that the supply, and management, of water is sustainable. The right words are used, suggestions are enthusiastically embraced and there is clear evidence that sustainability is considered a priority. In fact, there is almost an obsession towards developing and displaying sensitivity towards sustainability at all costs. Unfortunately, the real picture is not so rosy. Although water resources seem well managed, the impression is out of touch with reality. There is little economic growth, and social development is slow. The demand for water is growing quickly, and so problems are hiding just around the corner. The lack of acknowledgement of complexity results in government not taking into account the inherent unpredictability that characterises the water sector. There is an increasing inability to deal with the unexpected, and people within the management system operate in silos with little co-operation or sharing of knowledge. Similarly, any research that is encouraged is poorly directed, without any clear focus. The passion is there, but it is dispersed and diluted in effect. The resultant knowledge is not internalised, there is no time to reflect on decisions, and there is little innovation and new ideas to address pressing and emergent problems.

The driving feature of the story of the Ignorant Ostrich is the government's incapacity to prioritise water as central to development, and the rush to implement short-term and imbalanced solutions to the ever-growing challenges of a developing nation. In this scenario the forces entrusted with the management of water (the government) have a poor understanding of the concept of sustainability. They have 'more important issues' on their plate. There is frustration around general service delivery. People want taps, and they want them quickly. Little concern is afforded to the security, maintenance, quality, and assurance of the supply. As a result the government has been forced to make quick, and often rash, decisions surrounding water issues, hoping to secure quick results. The concept of sustainability is lost in the rush. If there is a key phrase in this scenario it is 'short-term'. Political and social imperatives for job creation and social and economic growth take precedence, with a view to 'improving the quality of life'; and when decisions are made they are designed to secure as much as possible as quickly as possible. In an attempt to accelerate delivery, work is going to the private sector (often via costly tender processes), which in turn increases complexity in the system and, subsequently, leads to higher transaction costs. The combination of a weak understanding of inter-generational equity and a lack of common vision, combined with an unyielding quest for short-term benefit, has placed a stranglehold around any considerations of sustainability for the water sector. While the little water that is left in the system bleeds out, the ostrich has not seen the danger signs and is unable to make decisions that allow for a sustainable and prosperous future for South Africa.

In the story of the Greedy Jackal, water is scarce. Resources are running dry in a country that is still in the process of development and addressing backlogs. The government is chiefly concerned with pandering to the social and economic demands placed upon it, and, as a result, represses any pressures for environmental responsibility. However, the prevailing mind set is not fatalistic. Something must be done, and a multidisciplinary approach is agreed upon. Learning is not through testing, but by doing. This is evident in increasing discourse around trade-offs, such as the sharing of resources, efficiencies and co-operations. Conflict increases between competing users, and the ideal has to be compromised at times to satisfy specific interests, be they economic, social, agricultural or even political. There is little agreement among stakeholders, and any decision-making is fragmented further by the vocal interference of lobby groups who seize the opportunity to pressurise malleable components of the decision-making process towards satisfying specific interests. South African citizens are confronted with tough decisions and are forced to rethink their cavalier attitude towards water. This is indeed a bitter way to learn about the critical nature of this limited resource. In frustration citizens turn to the government, who they see as the ultimate authority in the management of water. The government in turn centralises control and, in frustration, is unable to implement preferred measures, and thus suspends the National Water Act. 


\section{Discussion}

One of the objectives of scenario development is to identify preferred future outcomes and to navigate towards such outcomes through explicit decisions and actions. Signposts or indicators can be used to assess the current position and trajectory in the scenario game board. Indicators that suggest progression to the Wise Tortoise future can be expressed as the degree to which:

- Water is prominent in integrated planning through national strategies, with particular reference to water security.

- A systems approach and complexity thinking support a shared, principle-based vision and proactive adaptive management approach

- The National Water Resource Strategy is updated and implemented, through mature and stable institutions and stakeholders are empowered and accountable.

- Ministerial institutional instruments are in place.

- Legislation across sectors is harmonised to give effect to equitable and sustainable water resource-based social and economic development.

- There is effective informal governance and a strong citizens' voice.

- There is good support for research, knowledge is shared across disciplines and solutions which acknowledge complexity and sustainability are implemented.

- People have universal access to domestic water.

The Busy Bee scenario is characterised by the degree to which:

- Government is enthusiastic, with noble intentions to support sustainable development, but fails to take effective action.

- Social and economic growth is low and citizens do not see themselves as stakeholders.

- There is no complete picture of the water system, spatial planning is poor and there is an inability to deal with the unexpected.

- People have misguided views, are not in touch with reality and solutions are simplistic.

- Research is poorly directed, and while there are good intentions with projects to promote sustainable development, they are not aligned.

The Ignorant Ostrich path is defined by the degree to which:

- Water is not central to development and there is a poor understanding of sustainability.

- There is little concern for security, maintenance, quality and longevity of supply. Water comes out of a tap and everyone wants access, but the water supply is irregular, insufficient and degraded.

- The approach is short-term ('just do it'), with limited systems thinking which leads to imbalanced solutions and a weak understanding of intergenerational equity.

- There are no clear institutional systems in place, which results in poor institutional memory. International players are 'investing' for the wrong reasons and big business is 'calling the shots'.

- There is no acknowledgement of increasing complexity with the associated unpredictability leading to endless fire-fighting.

The traits of the Greedy Jackal scenario are the degree to which:

- Government is blamed and the National Water Act is 'suspended' with adaptive management becoming a reality in a context of water bleeding away and the wasteland encroaching.

- A multidisciplinary approach is agreed upon, but there is an increasing discourse around trade-offs, with the country still developing and addressing backlogs.

- New solutions need to be integrated, but shorter decisionmaking and response times are demanded, which means that innovation is key, but there are no resources to achieve innovation to support sustainable development.

- Water is scarce and the water sector is stressed, so citizens are forced to rethink their attitude towards water with water shortages escalating costs.

- There is an increase in conflict between competing users.

- Outbreaks of waterborne diseases prevail.

The present state of the water sector institutional landscape shares many traits with the Busy Bee scenario, although aspects of the other stories are also relevant in the current reality. The 'Proposed National Water Resource Strategy 2' (DWA, 2012) confirms this situation, stating that the complex physical, social and economic situation requires appropriate strategies, skills and capabilities. The Strategy also acknowledges the need for clear outcomes, monitoring, assessment and adaptive management, particularly in balancing social and economic benefits of competing water uses and ecological costs and benefits. The strategy further refers to the challenges in the implementation of the Reserve requirements and states that 'the stresses on water are increasing and water is not being managed in a sustainable manner' (DWA, 2012). This supports the authors' view of the current position of the water sector institutional landscape on the sustainable development axis. The path towards a preferred option (i.e. Wise Tortoise) requires the most significant interventions, such as real acknowledgement of complexity and the implementation of strategic adaptive management - in other words, the implementation and enforcement of the current policy. Inadequate action will move the sector to a worst-case scenario (i.e. Ignorant Ostrich). A push towards short-term, but inequitable, development will point towards the Greedy Jackal scenario.

The identification of sustainable development as a key driver of change is also supported by literature. The focus on sustainability gained public support with the publication of the book, Silent Spring (Carson, 1962), with the United Nations Conference on the Human Environment (UN, 1972) expressing a need for a common outlook to inspire and guide the peoples of the world in the preservation and enhancement of the human environment. The World Commission on Environment and Development also advanced this notion, saying that the strategy for sustainable development aims to promote harmony among human beings and between humanity and nature (Brundtland, 1987). The commitment to sustainable development was entrenched after the United Nations Conference on Environment and Development through the Rio Declaration and Agenda 21 (UN, 1992).

In conclusion, the scenarios and associated stories can be used by different actors in the water sector. Policy-makers (parliament and government) will benefit from a better understanding of the key forces that will define the future environment within which policies will be implemented. Such policies can then be tailored to be more effective in such an environment, but can also be adapted to counter undesirable trajectories of change. The scenarios will help regulators to identify possible conditions and issues that may prevail in the future. Regulations and operational plans can then be tailored 
to address these issues. The private sector and society can use the scenarios to plan for effective development outcomes under uncertain future conditions, but can also identify future risks and develop plans for mitigation of such risks. Scenarios can also create a societal impetus for a specific future, such as was the case with the 'high road' and 'low road' scenarios in the 1980s (Sunter, 1987), where citizens were confronted with distinct future possibilities and could make choices in accordance with a desired future state.

\section{Acknowledgements}

The authors would like to thank the Water Research Commission for providing funding, and in particular, Eiman Karar, for her guidance and technical support. The following organisations and individuals also contributed to various aspects of the development process, for which the authors are grateful: HSRC, Chantell Illbury, Barbara Heinzen, Elizabeth Masekoameng, Claudious Chikozho, Millicent Kekana, Jolandi Swanepoel, Devi Pillay, Mashadi Mogase, Zizi Ddlamini and Elise de Cock. Wilma Strydom provided valuable review comments and many people provided inputs through interviews, workshops and electronic communications. The authors are sincerely appreciative of these contributions of their time and knowledge.

\section{References}

BRUNDTLAND GH (1987) Address by Mrs Gro Harlem Brundtland, Chairman, at the Closing Ceremony of the Eighth and Final Meeting of the World Commission on Environment and Development, 27 February 1987, Tokyo, Japan. URL: http://www. academia.edu/1050424/World_Commission_on Environment and Development (Accessed 12 January 2013).

CARSON R (1962) Silent Spring. Hamish Hamilton, London.

CSIR (2010) A CSIR perspective on water in South Africa - 2010. CSIR Report No. CSIR/NRE/PW/IR/2011/0012/A. CSIR, Pretoria. ISBN: 978-0-7988-5595-2.

CLAASSEN M, FUNKE N and NIENABER S (2011a) The Water Sector 2025 - Institutional Landscape. WRC Report No. TT 514/11. Water Research Commission, Pretoria.

CLAASSEN M, FUNKE N and NIENABER S (2011b) The Water Sector Institutional Landscape by 2025. WRC Report No. 1841/1/11. Water Research Commission, Pretoria.

DACST (DEPARTMENT OF ARTS, CULTURE, SCIENCE AND TECHNOLOGY, SOUTH AFRICA) (1999) South African National Research and Technology Foresight Project. Department of Arts, Culture, Science and Technology, Pretoria.

DAUM J (2001) How scenario planning can significantly reduce strategic risks and boost value in the innovation chain. The New Economy Analyst Report - 8 September. URL: http://www.wecc. biz/committees/BOD/TEPPC/SPSG/051210/Lists/Minutes/1/3 The new New Economy Analyst Report.pdf (Accessed 12 January 2013).

DBSA (DEVELOPMENT BANK OF SOUTHERN AFRICA) (2011) Development Report 2011: Prospects for South Africa's future (Overview). Development Planning Division, Development Bank of Southern Africa, Halfway House.

DINOKENG TEAM (2009) 3 Futures for South Africa. URL: www. dinokengscenarios.co.za (Accessed 12 January 2013).

DWA (DEPARTMENT OF WATER AFFAIRS, SOUTH AFRICA) (2011) Annual Report of the Department of Water Affairs. Vote 37: 1 April 2010 to 31 March 2011. URL: http://www.dwa.gov.za/ Documents/RSP.aspx (Accessed 19 March 2012).
DWA (DEPARTMENT OF WATER AFFAIRS, SOUTH AFRICA) (2012) Proposed National Water Resource Strategy 2: Managing water for an equitable and sustainable future. Report issued to Cabinet, July 2012. Department of Water Affairs, Pretoria.

GRA (GLOBAL RESEARCH ALLIANCE) (2006) Science and Technology-based water scenarios for sub-Saharan Africa. URL: www.research-alliance.net (Accessed 19 March 2012).

HALVEY MJ and KEANE MT (2007) An assessment of tag presentation techniques. In: Proceedings of the 16th International Conference on World Wide Web, 8-12 May 2007, Banff, Canada. 1313-1314.

ILLBURY C (2011) Summary of Strategic Conversation Workshops. In: Claassen M, Funke N and Nienaber S (2012) The Water Sector Institutional Landscape by 2025. WRC Report No. 1841/1/11. Water Research Commission, Pretoria.

KAPLOWITZ MD, HADLOCK TD and LEVINE R (2004) A Comparison of web and mail survey response rates. Public Opinion 68 (1) $94-101$.

KAHANE A (1996) Learning from Mont Fleur: Scenario Thinking: Concepts and Approaches. Global Business Network, Emeryville, CA.

NPC (NATIONAL PLANNING COMMISSION, SOUTH AFRICA) (2011) National Development Plan: Vision for 2030. National Planning Commission. URL: www.npconline.co.za (Accessed 23 November 2011).

POLLARD S and DU TOIT D (2008) Integrated water resource management in complex systems: How the catchment management strategies seek to achieve sustainability and equity in water resources in South Africa. Water SA 34 (6) 671-680.

ROBERTS B, KIVILU M, DAVIDS YD (eds.) (2010) South African Social Attitudes: The 2nd Report. Reflections on the Age of Hope. Human Sciences Research Council, Pretoria. ISBN 0-7969-2217-9. $384 \mathrm{pp}$.

ROGERS K, BIGGS H and ROUX D (2000) Challenges for catchment management agencies: Lessons from bureaucracies, business and resource management. Water SA 26 (4) 505-512.

SADC (SOUTHERN AFRICAN DEVELOPMENT COMMUNITY) (2004) Regional Indicative Strategic Development Plan. Southern African Development Community. URL: www.sadc.int/index/ browse/page/104 (Accessed 23 November 2011).

SCHWARTZ P (1991) The Art of the Long View. Currency and Doubleday, New York.

SHELL (2003) Exploring the Future. Scenarios: An Explorer's Guide. Shell International Limited, London.

SNOWDEN DJ and BOONE ME (2007) A leader's framework for decision making. In: Harvard Business Review November 2007. $69-76$.

SOCIETY FOR INTERNATIONAL DEVELOPMENT (2005) The story of Uganda. URL: http://www.scenarios.ws/uganda/ (Accessed 23 November 2011).

SUNTER C (1987) The World and South Africa in the 1990s. Human Rousseau Tafelberg, Cape Town.

UNITED NATIONS (1972) Declaration of the United Nations Conference on the Human Environment. Stockholm, 5-16 June 1972. United Nations, Stockholm.

UNITED NATIONS (1992) Agenda 21. United Nations Conference on Environment \& Development, Rio de Janeiro, Brazil, 3 to 14 June 1992. United Nations, Rio de Janeiro.

UNITED NATIONS (2003) The United Nations World Water Development Report: Water for People Water for Life. UNESCO Publishing \& Berghahn books, Paris. ISBN: 92-3-103881-8.

WARFIELD J (1996) An Overview of Futures Methods. In: Slaughter $\mathrm{R}$ (ed.) The Knowledge Base of Future Studies. Vol 1-3. DDM Media, Melbourn

WBCSD (WORLD BUSINESS COUNCIL FOR SUSTAINABLE DEVELOPMENT) (2006) Business in the World of Water: WBCSD Water Scenarios to 2025. URL: www.wbcsd.org/web/ H2OScenarios.htm (Accessed 19 March 2012). 
http://dx.doi.org/10.4314/wsa.v39i1.14 Available on website http://www.wrc.org.za 